\title{
Sellar and parasellar lesions: multidisciplinary management
}

\author{
Lesioni della regione sellare e parasellare: gestione multidisciplinare \\ Enzo Emanuelli', Claudia Zanotti', Sara Munari', Maria Baldovin¹, Gloria Schiavo', Luca Denaro² \\ ${ }^{1}$ Department of Neurosciences DNS, Otolaryngology Section, Padua University, Padua, Italy; ${ }^{2}$ Department of Neurosciences DNS, \\ Neurosurgery Section, Padua University, Padua, Italy
}

\begin{abstract}
SUMMARY
Introduction. The endoscopic endonasal transsphenoidal approach to the sella and parasellar regions is now increasingly used for removal of a variety of lesions localized in the ventral skull base. The advantage of the endoscope is enhanced visualization and improved panoramic view that can result in more complete removal of the tumor. An extensive knowledge of the anatomy is mandatory to approach this region.

Materials and methods. From February 2009 to March 2020, the endoscopic endonasal approach was used in 153 patients with sellar and parasellar lesions, at our Institution: 136 pituitary adenomas, 7 craniopharyngiomas, 3 Rathke's cysts, a tuberculum sellae meningioma, an aneurysm of the internal carotid artery (ICA), a clivus chordoma, a papillary glioneuronal tumor, an histiocytosis, a pituitary metastasis from breast cancer and a chondrosarcoma.

Results. The most common surgical complications were cerebral spinal fluid leak (9), bleeding (2), pituitary abscess (2). Among endocrinological complications, the most important were diabete insipidus (23) and panhypopituitarism (3). Two patients complicated with meningitis. There were no visual worsening and no operative mortality. We had persistence of disease in 20 cases. Twelve patients underwent surgical revision for recurrence of the disease. Conclusions. Pre-operative planning and collaboration with several specialists are necessary in order to offer the patient the best treatment, minimizing complications.
\end{abstract}

KEY WORDS: skull base, sellar and parasellar region, pituitary adenoma, endoscopic endonasal approach

\section{RIASSUNTO}

Introduzione. L'approccio endoscopico endonasale trans-naso-sfenoidale alla sella e alla regione parasellare è a oggi l'approccio più utilizzato per lesioni localizzate nella parte ventrale della base cranica. Il vantaggio di questa tecnica consiste in una miglior visualizzazione panoramica del sito chirurgico che consente una rimozione quanto più completa del tumore. Un'approfondita conoscenza dell'anatomia è d'obbligo per iniziare ad approcciare questa regione.

Materiali e metodi. Da febbraio 2009 a marzo 2020, abbiamo trattato nel nostro Istituto 153 pazienti con lesioni sellari e parassellari mediante approccio endoscopico endonasale; di questi 136 erano adenomi dell'ipofisi, 7 craniofaringiomi, 3 cisti di Rathke, un meningioma del tubercolo sellae, un aneurisma dell'arteria carotide interna, un cordoma del clivus, un tumore glioneuronale papillare, un'istiocitosi, una metastasi pituitaria da cancro al seno e un condrosarcoma.

Risultati. Le complicanze chirurgiche più comuni sono state la rinoliquorrea (9), il sanguinamento (2), l'ascesso pituitarico (2). Tra le complicanze endocrinologiche, le più importanti sono state il diabete insipido (23) e il panipopituitarismo (3). Due pazienti si sono complicati con meningite. Non ci sono stati deficit visivi né mortalità intraoperatoria. Abbiamo avuto persistenza di malattia in 20 casi. Dodici pazienti sono stati sottoposti a reintervento per recidiva.

Conclusioni. Un'adeguata pianificazione preoperatoria e la collaborazione tra diversi specialisti sono necessarie per offrire al paziente il miglior trattamento possibile, riducendo al minimo le complicanze.

PAROLE CHIAVE: base cranica, regione sellare e parasellare, adenoma ipofisario, approccio endoscopico endonasale
Received: November 22, 2020

Accepted: February 18, 2021

\section{Correspondence}

Enzo Emanuelli

Department of Neurosciences DNS, Otolaryngology Section, Padua University, Padua, Italy

E-mail: enzoemanuelli@libero.it

Funding

None.

Conflict of interest

The Authors declare no conflict of interest.

How to cite this article: Emanuelli E, Zanotti C, Munari S, et al. Sellar and parasellar lesions: multidisciplinary management. Acta Otorhinolaryngol Ital 2021;41(SUPPL.1):S30-S41. https://doi.org/10.14639/0392-100X-suppl.1-41-2021-03

(C) Società Italiana di Otorinolaringoiatria e Chirurgia Cervico-Facciale

\section{(c) (1) $(2)$}

This is an open access article distributed in accordance with the CC-BY-NC-ND (Creative Commons Attribution-NonCommercial-NoDerivatives 4.0 International) license. The article can be used by giving appropriate credit and mentioning the license, but only for non-commercial purposes and only in the original version. For further information: https:// creativecommons.org/licenses/by-nc-nd/4.0/deed.en 


\section{Introduction}

The sphenoid bone sits at the center of the skull base, representing the fulcrum of this region and the border point between the anterior and middle cranial fossa. The sella turcica is a bone depression included between the anterior and posterior clinoid processes of the sphenoid bone. It represents the central portion of the middle cranial fossa and contains the pituitary gland. Laterally to the sella turcica, along the fusion line between the body of the sphenoid and greater wings, there is the carotid sulcus for the passage of the parasellar portion of the internal carotid artery (ICA).

The pituitary gland is composed of two parts: the adenohypophysis (anterior lobe), which represents about $70 \%$ of the volume of the entire gland and the neurohypophysis (posterior lobe).

A semitransparent, thin but tight capsule surrounds the gland's surface. The pituitary gland is completely surrounded by dura mater: its anterior, inferior and posterior walls are surrounded by a double layer and by sellar bone; on the contrary, the upper and lateral walls are covered only by dura mater and both offer less resistance to tumour growth ${ }^{1}$.

The upper wall which forms an inextensible diaphragm, is thick at the periphery, thin at the centre, where it is depressed and perforated by the hypothalamus-pituitary stalk. Anteriorly the two layers of dura mater continue with the dura mater covering the sphenoidal planum and the anterior cranial fossa, posteriorly they continue with the dura of dorsum sellae and clivus. Laterally, the two layers separate: the outer periosteal layer continues laterally to form the sphenoidal or anterior wall of the cavernous sinus, while the inner meningeal layer remains attached to the gland and runs backwards towards the posterior clinoid process and the dorsum sellae to form the medial wall of the cavernous sinus. Consequently, both walls (anterior and medial) of the cavernous sinuses are made up of a single layer of dura mater ${ }^{2}$. The arachnoid is located just above the diaphragm and, therefore, there is usually no liquor inside the sella.

The parasellar region includes all the structures surrounding the sella turcica ${ }^{3}$ : the suprasellar region at the top, the two cavernous sinuses laterally, and the clival region at the bottom. It represents a crossroads region where a high number of neoplastic, inflammatory, infectious and vascular diseases can develop ${ }^{4}$.

The suprasellar region extends above the sellar diaphragm to the floor of the third ventricle and contains the optic chiasm, optic nerves, the pituitary stalk and the Willis' circle. It is close to the third ventricle, the hypothalamus, the tuber cinereum and the mammillary bodies. The most common lesions of this region are:
- suprasellar extension of pituitary adenomas;

- craniopharyngiomas;

- hypothalamic or optic chiasm gliomas;

- hamartomas;

- germinomas;

- dermoid and epidermoid tumors.

The cavernous sinuses, two venous structures that delimit the pituitary fossa laterally, are in relationship with the following cranial nerves: oculomotor (III), trochlear (IV), first and second branches of the trigeminal nerve (V1 and V2), and abducent (VI). All the nerves are contained in the lateral wall of the cavernous sinus, except the abducent nerve which is located laterally to the carotid artery and medially to V1. Within the cavernous sinus there is also the cavernous carotid artery (with three segments and two genua) and its branches. The lesions that most affect the cavernous sinuses are:

- lateral extension of pituitary adenomas;

- meningiomas;

- schwannomas;

- aneurysms of the ICA.

Clivus is a bony portion behind the dorsum sellae that slopes obliquely backward to the magnum foramen getting in touch with the ventral face of the brain stem. The clival region extends inferiorly to the dorsum sellae and includes the sphenoid sinus, the nasopharynx and the clivus. The most common lesions of this region are:

- chordomas;

- chondrosarcoma;

- meningiomas;

- nasopharyngeal carcinomas;

- tumors of the sphenoid sinus;

- mucoceles;

- juvenile angiofibromas.

Histology of sellar and parasellar lesions is heterogeneous but the main role is played by the pituitary adenomas; however, in $9 \%$ of cases we find different histologies with peculiar biological features that is essential to know for adequate surgical treatment (Tab. I). The biological variety does not reflect the clinic, since symptoms of sellar and parasellar neoplasms depend on the sub-site of origin: in this particular district, knowledge of the anatomy is essential not only for surgical purposes, but also to define the clinical picture.

The radiological study plays a key-role in the diagnostic framework of these pathologies. The Magnetic Resonance Imaging (MRI) with gadolinium and the Computer Tomography (CT) scan are complementary: the first provides information about the nature of the lesion and the involvement of vital structures; the second defines in detail the bone involvement and allows to identify the possible presence of intralesional calcifications. 
Table I. Main lesions of sellar and parasellar region.

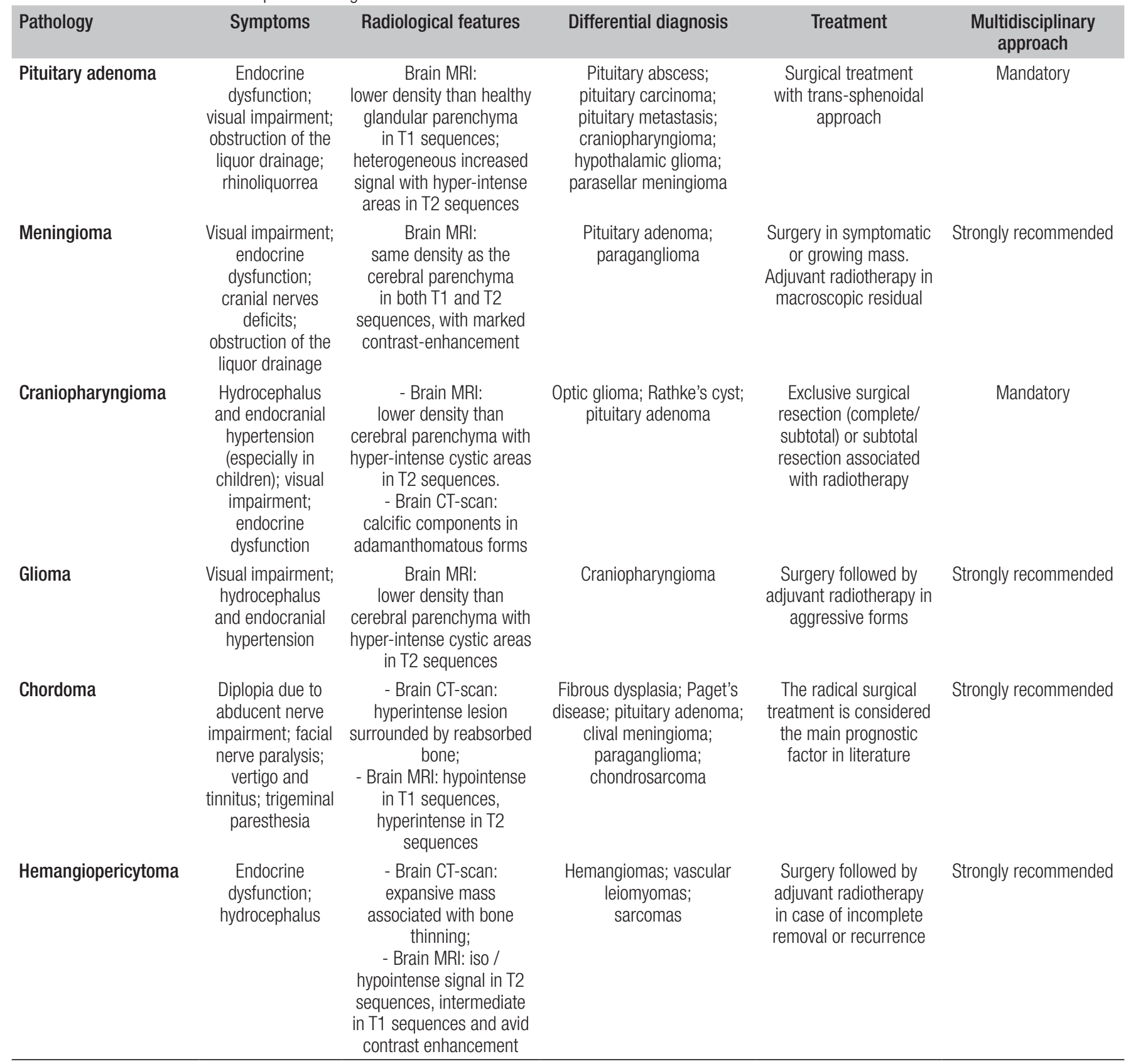

\section{Materials and methods}

Since February 2009, a collaboration between our Otorhinolaryngology, Neurosurgery Academy and Endocrinology Units has been started for the management of sellar and parasellar pathologies. From this date to March 2020, a total of 153 patients underwent endoscopic trans-sphenoidal surgery. 136 patients (89\%) were affected by pituitary adenomas, the remaining 17 patients was affected by the following: 7 craniopharyngiomas, 3 Rathke's cysts, a tuberculum sellae meningioma, an aneurysm of the ICA, a clivus chordoma, a papillary glioneuronal tumour, an histiocytosis, a pituitary metastasis from breast cancer and a chondrosarcoma.

Multidisciplinary management is necessary for the correct approach to the patient and pathology. The specialists involved are Endocrinologist, who often refers the patient for surgical evaluation and requires complete serum pituitary 
hormone panels both pre and postoperatively, Neuroradiologist for imaging evaluation of the lesion and anatomy, Neurosurgeon for four-hands technique which we always perform, and the Ophthalmologist in case of visual impairment at diagnosis.

A multidisciplinary skull base conference meets twice a month to discuss the cases. Then, all patients undergo an endoscopic endonasal approach, which provides the most direct access to the ventral skull base while obviating the need for retraction and manipulation of critical neurovascular structures.

The trans-sphenoidal approach performed by an expert surgeon is nowaday a safe procedure, with a remission rate from $42 \%$ to $95 \%$, depending on the case studies (with most between 70-85\%) ${ }^{5}$. This surgical technique can be divided into three phases: nasal, sphenoidal and sellar.

Nasal phase: two endoscopic approaches can be used to reach the sellar region.

The paraseptal trans-sphenoidal approach tangent to the nasal septum removing the upper turbinate body (or supreme, when present) represents the preferred choice. If the anatomy avoids an easy approach to the sphenoid sinus, for example in case of nasal septum deviations, the posterior third of the nasal septum can be removed to obtain a wider route, to use the four-hand technique.

The trans-ethmoid-sphenoidal approach is useful when more space is necessary or in the laterally extended transpterygoidal approaches.

Once the sphenoid ostium or anterior sinus wall has been identified, the surgical procedure is the same for both approaches.

Sphenoid phase: the anterior wall of the sphenoid sinus is opened using a Kerrison's rongeur to expose the anterior margin of the intersphenoidal septum. The mucosa is preserved to save the nasal branch of the sphenopalatine artery. The sphenoidal septum and rostrum must be gently removed because they can be connected with ICA. The anatomical landmarks of the lateral wall of the sphenoid sinus are now visible (Fig. 1). The bony irregular edges are then carefully drilled out to obtain a wide access to the sellar floor. When tumours develop into cavernous sinus, more bone must be removed in the lateral direction towards the anterior face of the parasellar carotid artery; when tumours reach the suprasellar region, sellar floor removal is required.

Sellar phase: once the dura mater is exposed, a cross incision is made to avoid damage to the carotid artery and the anterior arachnoid cistern. From now on the four-hands technique with the Neurosurgeon is applied to remove the tumor. The lesion is detached using ring-shaped curettes: in case of pituitary adenoma, it can be identified as a greyish region in contrast with the pink colour of the gland and for its soft consistency (Fig. 2). The adenomatous tissue is carefully separated from the glandular tissue using a microdissector and removed en bloc. The advantage of a dissection along the pituitary pseudo-capsule in order to completely remove the lesion and reduce tumour residue has been demonstrated ${ }^{6-10}$. Once the lesion is totally excised, the inspection of the sellar cavity with angled optics and hydrodissection is mandatory, paying attention to the suprasellar and cavernous sinus areas.

A variety of thoroughly evaluated techniques exist to close the skull base defects, depending on the location and the size of the defect. We always prefer autologous grafts (bone of the middle turbinate, mucoperiosteum, septal cartilage and mucopericondrium) or other autologous materials (such as fascia lata or rarely fat), that allow highly compatible repair of the dura and can be readily harvested compared to heterologous grafts. The area of the defect must be prepared: the mucoperiostium surrounding the defect
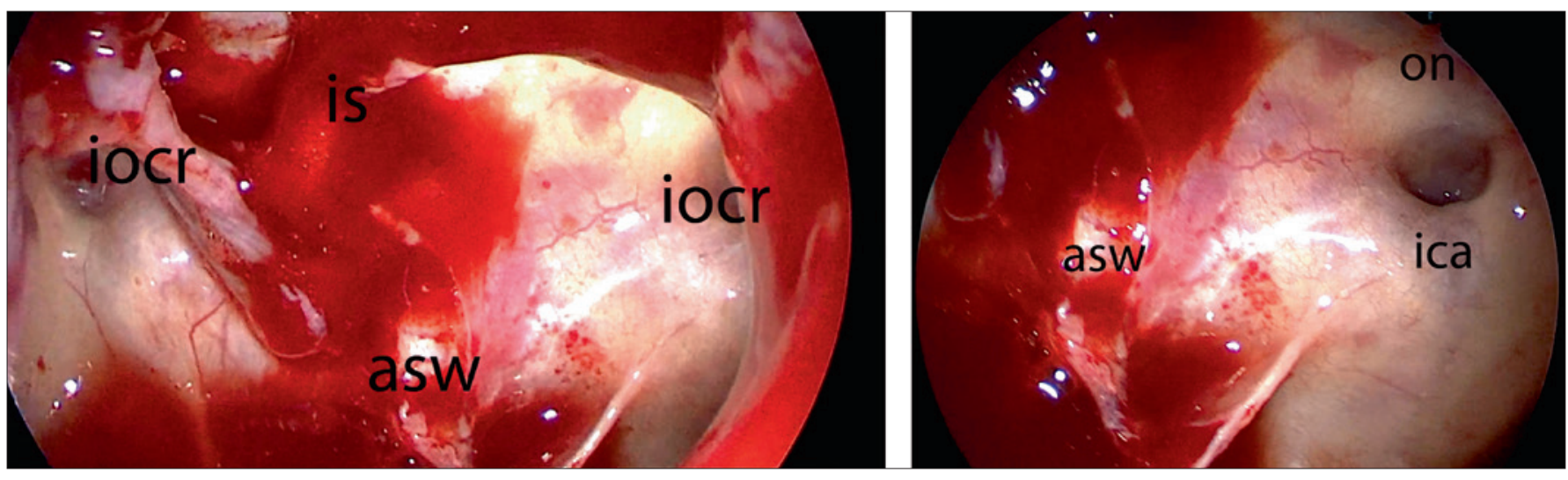

Figure 1. Sphenoidal sinuses after drilled out the intersphenoidal septum - asw: anterior sellar wall; ica: internal carotid artery; on: optic nerve; iocr: interopticcarotid recess. 

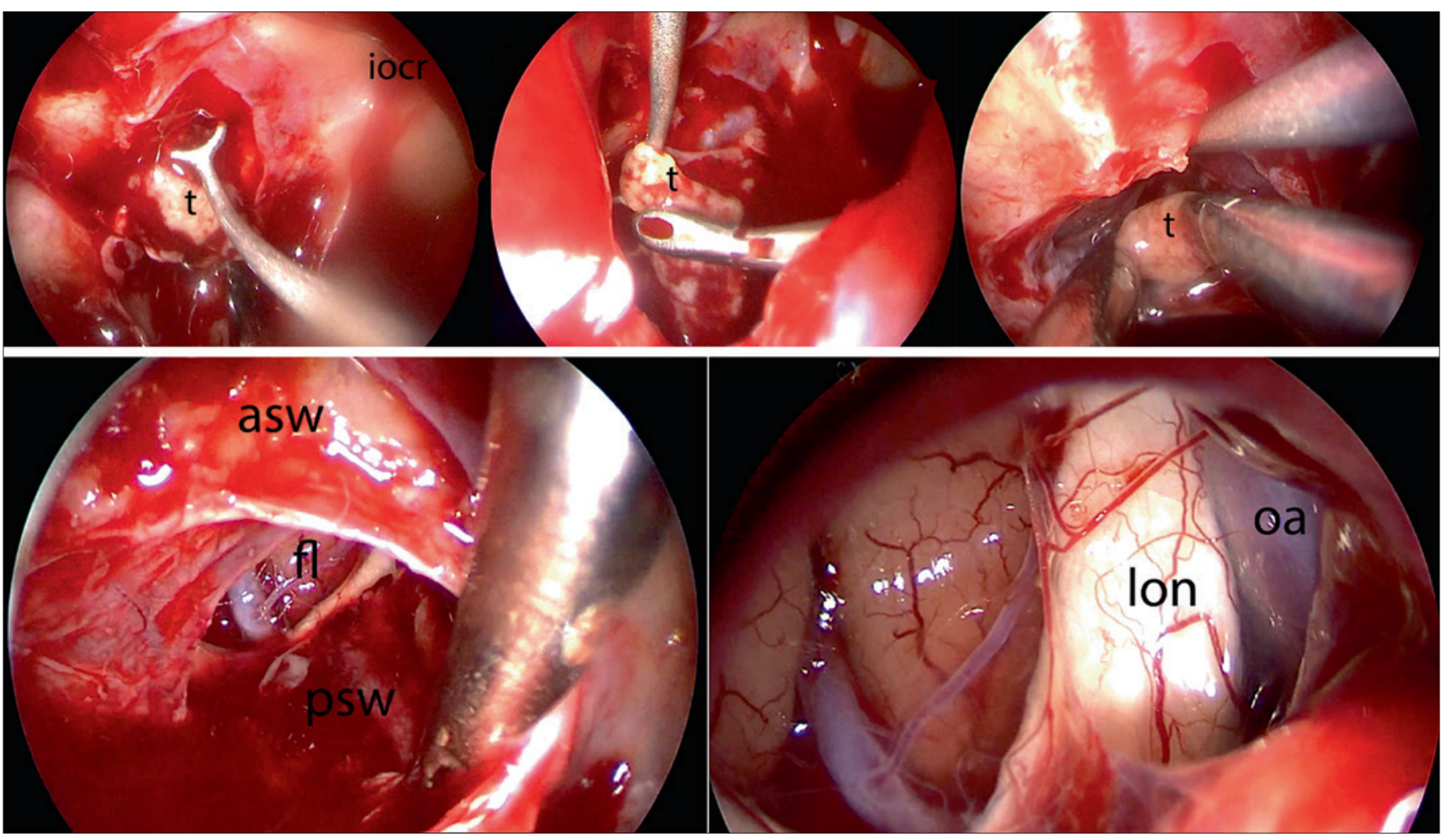

Figure 2. Removal of the tumour ( $\mathrm{t}$ ) with four hands technique and vision at the end of the procedure with a $0^{\circ}$ and $45^{\circ}$ telescopes - asw: anterior sellar wall; psw: posterior sellar wall; fl: frontal lobe; lon :left optic nerve; oa: ophtalmic artery.

is detached with straight and angled dissectors in order to expose the bone and locate the dural defect (Fig. 3). When no cerebrospinal fluid (CSF) leak or dripping is confirmed by the Valsalva maneuver, we use autologous endonasal tissues positioned undelay (intracranially extradurally). When moderate or massive CSF leak is present, a multilayer technique is preferred using fascia lata positioned underlay and septal cartilage or bone from the middle turbinate positioned immediately above the first layer. A further layer of fascia lata is positioned overlay (extracranially extradurally), covered by mucoperiosteum or mucopericondrium. Considering that fascia lata physiologically shrinks, grafts larger than $30 \%$ of the dura defect must be removed. In case of massive CFS leak or high flow defect, the Hadad flap vascularized on the nasal branch of the sphenopalatine artery can be prepared.

Once repaired the defect, the surgical field is gently filled with absorbable sponge material that maintains the correct positioning of the grafts.

This study was conducted in compliance with the Declaration of Helsinki. Written informed consent was obtained from all patients.

\section{Results}

Of the 153 patients operated, 56 were males and $97 \mathrm{fe}$ males. The mean age at the time of diagnosis was $49 \pm 13$ years. In 35 cases the lesion was a recurrence of previous surgery performed elsewhere.

Of the 136 patients affected by pituitary adenomas, 43 were microadenomas and 93 macroadenomas, divided as follows: 50 non-secreting tumours, 43 ACTH-secreting adenomas, $27 \mathrm{GH}$-secreting adenomas, 6 PRL-secreting adenomas, 4 TSH-secreting adenomas, 1 FSH-secreting adenomas and 5 mixed lesions (3 GH-PRL, 1 TSH-GH and 1 TSH-FSH).

Considering all the patients, endocrinological disorders such as acromegaly, Cushing's disease, panhypopituitarism, hyper- or hypothyroidism, insipidus diabetes, decreased libido, amenorrhea and galactorrhea were the most frequent symptoms. In 9 cases the tumour was incidentally found during a brain imaging performed for other reasons. Sexteen patients also referred visual impairment such as homonymous or bitemporal hemianopsia or decrease in visual acuity (usually unilateral): in 12 cases the post-surgical visual recovery was complete while in 2 cases it was partial; in 2 patients there was no improvement. 


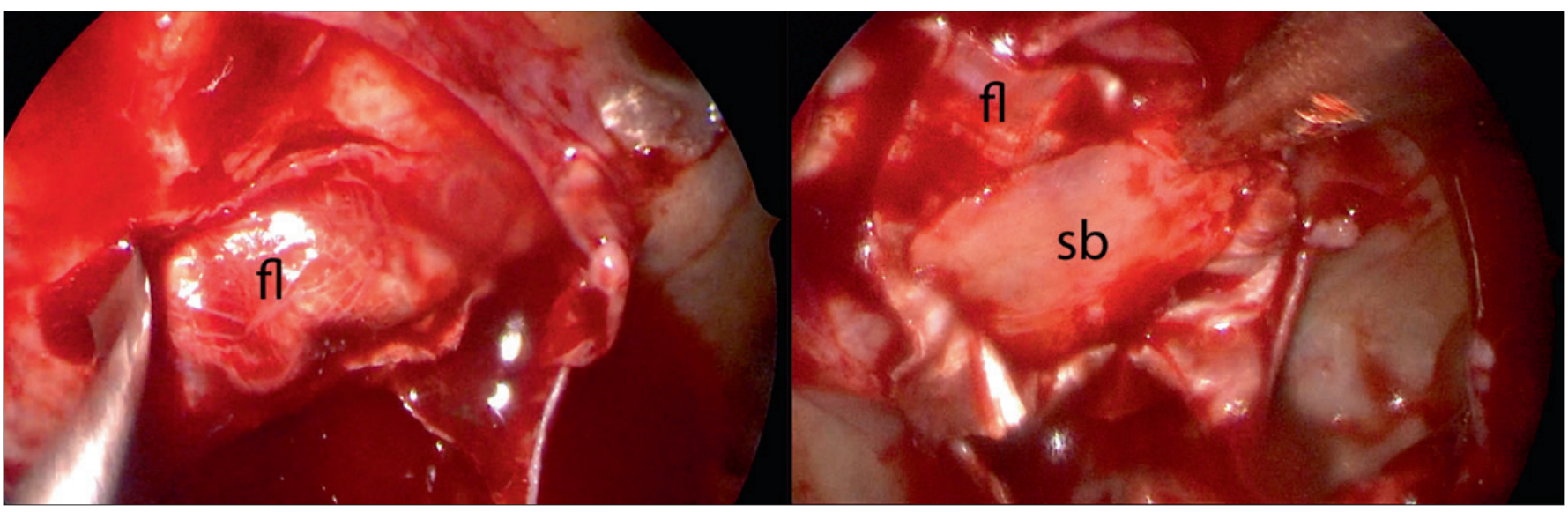

Figure 3. Reconstruction of the anterior wall of the sella with a multilayers technique - fl: fascia lata; sb: septal bone.

Based on the extension and histologic type of the tumor, we decided to perform a paraseptal approach tangential to the nasal septum for purely sellar lesions (136 cases), or a transethmoidal approach for lesions extending laterally into the cavernous sinus (8 cases). Extended endoscopic transsphenoidal approach was preferred for suprasellar and clival lesions ( 9 cases).

Endoscopic endonasal examination was performed on the $15^{\text {th }}$ and $30^{\text {th }}$ postoperative day, then every month during the first six months and every three months during the first year; every six months for the second year and annually thereafter. In our case series, the postoperative follow up period ranged from 9 to 132 months.

Follow-up includes endocrinological evaluation with complete hormonal assessment at 30 days, within three months and then at 6-months intervals, to assess any persistence or recurrence of disease.

Neuro-ophthalmologic evaluation was required three months after surgery only for those who had visual impairment preoperatively, or at any time for patients who reported alterations of new onset.

The most common surgical complications were:

- epistaxis, which required transfusion in one case and caustication of the sphenopalatine artery in another case;

- cerebrospinal fluid leaks (9 cases) with surgical revision of the dural plasty repaired with a multilayer technique using autologous fascia lata, cartilage or bone (from turbinates or septum) and mucoperiosteum from the inferior turbinate. Hadad flap was used in 3 cases, when a high flow leak was present;

- pituitary abscess (2 cases), the fist successfully treated with surgical drainage, the second quickly complicated in a brain abscess leading to coma and subsequent patient's death.

Among the endocrinological complications, we had dia- bete insipidus in 23 patients (most of which transient) and panhypopituitarism in 3 patients. Two patients complicated with meningitis.

Brain MRI performed 4 months after surgery showed persistence of disease in 20 patients, 4 of which were ACTHsecreting adenomas: in most cases it was intentionally left during surgery, in order to avoid damage to neuro-vascular structures close to the tumour. Twelve patients underwent surgical revision for recurrence of the disease.

\section{Discussion}

The skull base represents the boundary between the intracranial and facial region and is crossed by important neurovascular structures that enter and leave the brain through bone foramina. For this reason, this anatomical area is one of the most complex to treat surgically. The pituitary gland, enclosed in the sella turcica, is located at the center of the skull base: the extension of any pathology at this level can lead to endocrinological dysfunctions of hyper or hypo-secretion. Lateral to the gland there are the cavernous sinuses, which contain the III, IV and VI cranial nerves and the first and second branches of the trigeminal nerve. Therefore, the involvement of a cavernous sinus will be reflected in the alteration of ocular motility and consequent diplopia. The VI cranial nerve is the most frequently involved, due to its completely intracavernous course. The involvement of intracavernous ICA rarely causes clinical manifestations. Sometimes, pupillary defects can occur, due to irritation or deficit of the pericarotid sympathetic plexus. The suprasellar region houses many important structures, first of all the optic nerves, tracts and chiasm: a neoplasm at this level can appear with visual impairment; moreover, the hypothalamus, which can lead to various diseases: endocrinological dysfunctions such as hypopituitarism due to 
hypo-secretion of the release factors or diabetes insipidus for the interruption of the hypothalamic-pituitary stalk, furthermore, alterations of thermoregulation and metabolism. It is also essential to remember the close relationship of the suprasellar region with the third ventricle: an expanding lesion at this level can obstruct the liquor's circulation increasing the intracranial pressure ${ }^{11}$. Finally, large tumours can grow in the clival region, involving the apex and the endocranial surface of the petrosal bone with trigeminal nerve compression at the Cavum Meckel, facial and vestibulocochlear nerves deficit, compression of the jugular vein's bulb or mixed nerves at the level of posterior foramen lacerum, even symptoms of nasal obstruction in case of massive growth towards the nasopharynx.

Below, are briefly analysed the main lesions that can affect this complex anatomical district.

\section{Benign tumours}

Pituitary adenomas: they are the most frequent neoplasm of the sellar region, with possible parasellar extension. Signs and symptoms can be determined by tumour hormonal hyper-secretion, reduced hormonal secretion (due to the compression on healthy glandular tissue), compression of the surrounding structures from an extrasellar adenoma.

The expansion can occur in all directions: caudally, the lesion can cause thinning of the sellar floor and occupy the sphenoid sinus and the nasal cavities, with nasal obstruction, epistaxis and/or rhinoliquorrea.

Cranial growth can cause symptoms of optic-chiasmatic compression (bitemporal or homonymous hemianopsia), hypothalamic compression (hypersomnia, alterations of hydro-electrolytic balance and metabolism), or obstruction of the liquor drainage (hydrocephalus, intracranial hypertension) (Figs. 4-6). The Hardy's classification describes four levels of suprasellar extension depending on the relationship between the neoplasm and the optic chiasm ${ }^{12}$.

The lateral development of the adenoma can cause compression of the cavernous sinus or epilepsy if the temporal lobe is achieved. The classification system used to define the involvement of the cavernous sinus is the Knosp's classification ${ }^{13}$, which recognises four levels of lateral extension according to the relationships between the tumour and the ICA at MRI coronal sections.

In some cases, acute pituitary apoplexy can occur, with sudden blindness and acute hypopituitarism ${ }^{14}$.

Preoperative brain MRI is essential for diagnostic workup. In $\mathrm{T} 1$ sequences, the density of the adenoma is lower than healthy glandular parenchyma, while it has an increased signal in the T2 sequences. Macroadenomas often show a heterogeneous signal, particularly in T2 sequences, with hyper-intense areas corresponding to cystic, necrotic or haemorrhagic areas ${ }^{14}$. CT scan offers complementary information to MRI, since it provides a better definition of the bone landmarks for the surgical approach. In case of suprasellar lesion close to the optic chiasm, a pre-operatory visual examination with Hess screen is necessary. Moreover, young patients with family history of pituitary adenomas or other endocrinological pathologies (primary hyperparathyroidism, neuroendocrine neoplasms) should undergo genetic investigations for mutations of the AIP, MEN1 and MEN4 genes research.

In the differential diagnosis of a non-typical sellar mass, pituitary abscesses, pituitary carcinomas, pituitary metastases from primitive other tumors (especially breast and lung), craniopharyngiomas, hypothalamic gliomas, parasellar meningiomas must be considered. In most cases, differential diagnosis is based on clinical and radiological features ${ }^{15}$.

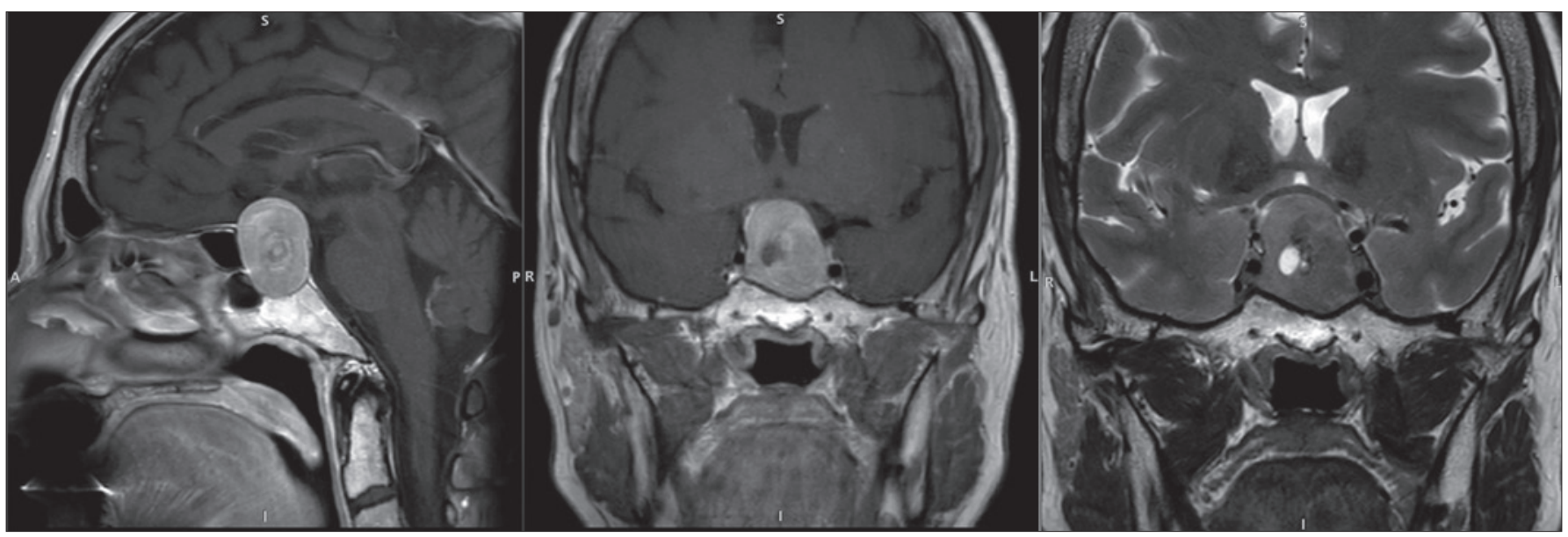

Figure 4. Sagittal and coronal MRI T1 with gadolinium and coronal T2 views showing a macroadenoma stretching upward the optic chiasm. 


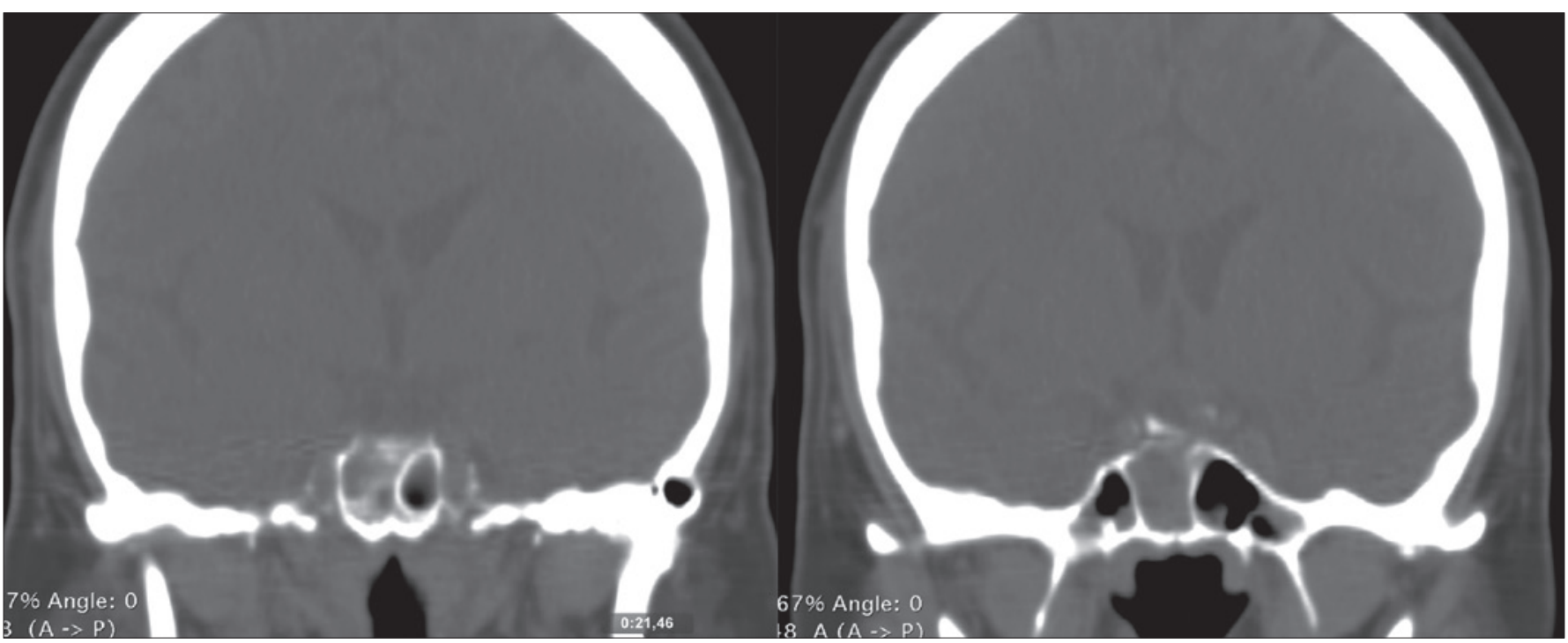

Figure 5. Brain CT-scan 6 hours after surgery showing complete removal of the tumour.

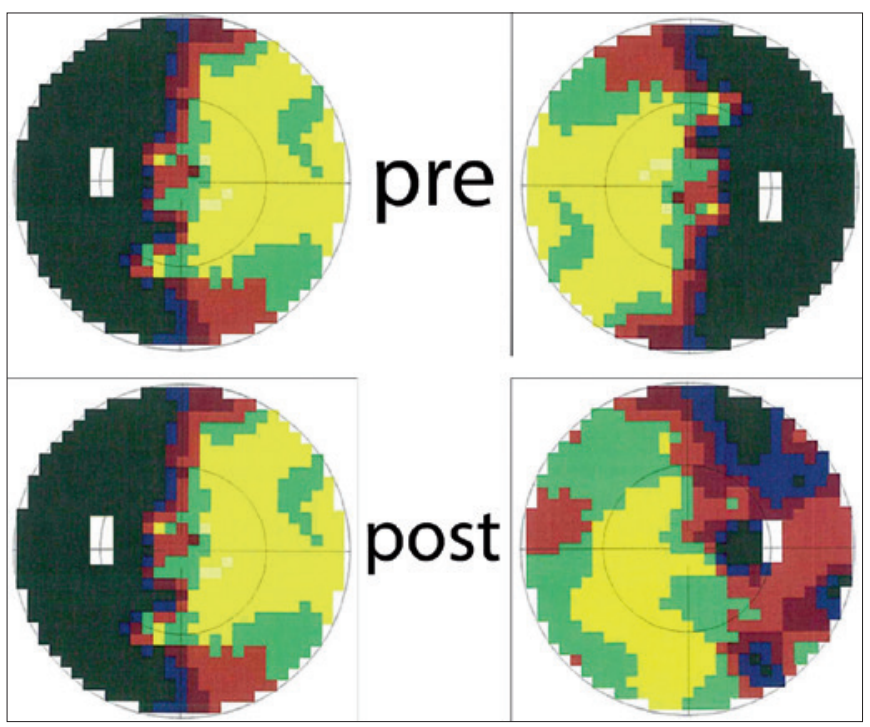

Figure 6. Visual field pre surgery and ten days after surgery.

Meningiomas: they originate from arachnoid cells located in the Pacchioni's bodies. They represent $13-25 \%$ of all primary intracranial tumours ${ }^{16}$, the second most common neoplasm of the parasellar region, after pituitary adenomas, with an incidence peak between the sixth and the seventh decade of life. Meningioma in children is mainly linked to genetic diseases, especially neurofibromatosis type $2{ }^{17}$. The World Health Organization distinguishes 3 categories of meningiomas ${ }^{18}$ :

- Grade I: benign meningiomas ( $92 \%$ of cases);

- Grade II: atypical meningiomas (5-7\% of cases);

- Grade III: anaplastic meningiomas (1-2\% of cases).
To define a meningioma as atypical, a high mitotic index or cellular atypical features such as an increased nucleus/ cytoplasm ratio or high cellularity must be found. Anaplastic meningiomas have a clearly malignant appearance and behavior.

In sellar and parasellar region, these lesions can originate from the sellar diaphragm, the sellar tuberculum, the anterior clinoid process and the medial portion of the small wings ${ }^{19}$. Symptoms are related to compression of the surrounding structures, such as visual impairment, hormonal or cranial nerve deficits. The gold standard for the radiological study is MRI: the meningioma shows the same density as the cerebral tissue both in T1 and T2 sequences, with an intense contrast-enhancement. Surgery is the therapy of choice in symptomatic or growing lesions. Adjuvant radiotherapy can be used in selected cases of macroscopic residual after surgical resection.

Craniopharyngiomas: they are slow-growing epithelial tumours from ectopic embryonic cells of the pituitary recess. Despite benign histology, these lesions have an aggressive behaviour since they localize and grow close to critical neuro-vascular structures. The incidence is bimodal with a peak between 5 and 14 years and between 50 and 74 years ${ }^{20}$. Most craniopharyngiomas develop in suprasellar region, with possible extension in all directions, rarely totally intrasellar. In children, craniopharyngiomas represent $1-4 \%$ of all brain tumours and the prevalent histology is adamanthomatous, typically associated with cystic and calcific components at CT-scan imaging. The cystic growth inside the third ventricle causes the occlusion of the Monro's foramen and consequent hydrocephalus with signs of 
endocranial hypertension, that is the more frequent presentation of craniopharyngiomas in pediatric patients. Craniopharyngiomas represent $1.2-4 \%$ of all adult intracranial tumours and the most common histology is papillary, characterized by squamous cells nests surrounded by stromal tissue ${ }^{21}$. In adult patients, the typical symptoms are visual impairment and endocrine dysfunction. The main problem of treatment is the need for radical excision avoiding damage to the surrounding structures. The therapeutic options are exclusive surgical resection (complete or subtotal) or subtotal resection associated with radiotherapy.

According to a review conducted by Clark et al. ${ }^{22}$, in pediatric patients the recurrence of craniopharyngiomas amount to $35 \%$ after a gross total resection, while in case of subtotal resection it is $65 \%$, and becomes $50 \%$ if surgery is combined with adjuvant radiotherapy; furthermore, the two options are not significantly different in terms of 5-year disease-free survival. Five-year overall survival is estimated to be $83-96 \%$, but in the review they did not consider the long-term morbidity and quality of life after the treatment. Surgery is considered the gold standard for recurrence, with more surgical risks and greater morbidity due to anatomical alterations caused by previous treatments. Postoperative radiotherapy is the choice for residual disease.

Rathke cleft cyst: it is a congenital lesion from the embryonic Rathke's cleft. Although these lesions are mainly asymptomatic, they can suddenly grow due to intralesional bleeding or infection causing endocrine dysfunctions. Therapy is surgical excision.

Schwannomas: they are rare parasellar tumours, usually from the first and second branches of the trigeminal nerve in the Cavum Meckel, rarely from the nerves of oculomotion. They are characterized by slow growth with surrounding bone thinning. Surgical therapy is preferred for progressive forms.

\section{Malignant tumours}

Gliomas: they are slow-growing tumours arising from the hypothalamus, the optic chiasm or the optic tract. The most common histology is low-grade pilocytic astrocytoma, considered a benign tumour and related to neurofibromatosis type 1 in one third of cases. The median survival is 7 years ${ }^{23}$ and only in advanced stages they present classic signs of hypothalamic or optical pathways impairment. There is also a small share of high-grade gliomas (multiform astrocytomas and parasellar glioblastomas) with a shorter median survival (11.2 months). Therapy is surgery followed by adjuvant radiotherapy for aggressive forms.

Chordomas: they are slow-growing lesions from residues of the notochord. They have low tendency to distant metastases, but a local aggressive behaviour. Three histopathologi- cal variants are recognized: the classic form, characterized by nests of eosinophilic cells in a basophilic/myxoid background; the chondroid form, with chondroid differentiation of the matrix; and the dedifferentiated form, which has a malignant fusiform cells component with sarcomatous features. These tumours are mainly localized in the clivus.

Symptoms can occur late, in most cases with headache or cranial nerves defects: the most affected is the abducent nerve with diplopia, but paralysis of the facial nerve, vertigo, tinnitus and paresthesia can also occur due to the close relation with the posterior cranial fossa. Clival chordomas may also present with a spontaneous CSF leak. On CT-scan the lesion appears hyperintense expansive, destructive and lytic, with irregular areas of calcification within the tumour. MRI better defines the relationships with surrounding structures. In T1 sequences, the lesion appears hypointense with hyperintense components corresponding to bleeding areas; while in $\mathrm{T} 2$ sequences the lesion is hyperintense. Usually the tumour presents an avid contrast enhancement unless the necrotic component is predominant.

The differential diagnosis must consider all the benign and malignant bone neoplasms, such as fibrous dysplasia or $\mathrm{Pa}-$ get's disease, or pituitary adenomas with caudal extension, clival meningiomas, paragangliomas or chondrosarcomas. Because of the high rate of recurrence, surgery must be as radical as possible, followed by adjuvant radiation therapy (conventional or adrotherapy, preferably) ${ }^{24}$. In the literature, complete resection is considered one of the main prognostic factors.

Chondrosarcomas: they originate from residual embryonic mesenchymal tissue of the cranial cartilage at the level of the petro-occipital and spheno-petrosal sutures. Often mistaken for chordomas, they have a more aggressive behavior and a faster growth: this paradoxically involves an earlier diagnosis and a better prognosis than chordomas ${ }^{25}$. Differentiating between chordomas and chondrosarcomas is imperative as they have different behaviors and treatment response: chordomas tend to be median lesions with an epicenter at the clivus and spheno-occipital synchondrosis, whereas chondrosarcomas often have an epicenter at the petroclival synchondrosis.

Germ cells tumours: the most representative histology is the germinoma, a midline tumour typical of the pineal area, which can affect the suprasellar region in $20 \%$ of cases ${ }^{4}$. The remaining histologies are extremely rare at this level and include embryonic cell carcinomas, choriocarcinomas and teratomas. Chemo-radiotherapy represents the treatment of choice, surgery is often necessary to obtain a definitive diagnosis.

Hemangiopericytomas: they are highly vascularized and locally invasive lesions. In the parasellar region they are mostly located above the sellar diaphragm. They originate 
from the pericytes, mesenchymal cells surrounding the endothelium of capillaries and blood vessels. Their behaviour is borderline, classified as low-grade sarcomas. The prevalence is slightly higher in women with a peak of incidence in the sixth-seventh decade of life. At the CT-scan the lesion appears as an expansive mass associated with bone thinning, the MRI confirms the solid nature of the lesion with iso/hypointense signal in T2 sequences, intermediate in $\mathrm{T} 1$ sequences and avid contrast enhancement ${ }^{26}$. Macroscopically, hemangiopericytoma appears as non capsulated but well-defined subepithelial lesion, with a typical perivascular growth. Differential diagnosis includes vascular lesions, such as hemangiomas or vascular leiomyomas, and mesenchymal masses, such as sarcomas or solitary fibrous tumours. Only histology can confirm the diagnosis and drive the treatment. Nowadays, there is no well-coded classification system for these lesions; some authors have proposed the Kadish classification, even if the correlation between stage and prognosis has not been demonstrated. The treatment of choice is surgical, while post-operative radiotherapy is indicated in case of incomplete removal or recurrence. The prognosis is excellent with a 5-year disease-free survival more than $90 \%$ in total resection ${ }^{27}$. Local recurrence, however, is reported in the literature up to $40 \%$ of cases and even 5 years or more after surgery ${ }^{28}$. Some histopathological features such as size $>5 \mathrm{~cm}$, bone invasion, nuclear polymorphism, increased mitotic activity, proliferation index $>10 \%$ are typical of the more aggressive forms ${ }^{29}$.

Langherans' cells histiocytosis: it is a rare systemic disease characterized by the proliferation of dendritic cells of the epithelial immune system. It should be reminded for the peculiar tendency of this tumour to involve the hypothalamus and the posterior pituitary lobe, causing diabetes insipidus as single manifestation. Therapy is exclusively medical.

Lymphomas: large B-cell lymphomas located in the cavernous sinus and in close relation with the pituitary gland are described in the literature. Surgery has only diagnostic purpose. Metastases: in most cases metastases in the pituitary gland derive from breast in women and lung in men, while metastases in the parasellar region are very rare (less than $1 \%$ of patients undergoing transnasal surgery).

\section{Treatment}

Since the $18^{\text {th }}$ century, surgeons from different disciplines experimented with various approaches to the base of the skull. Francesco Durante, general surgeon from Sicily, in 1883 was the first who successfully removed an anterior cranial fossa meningioma with a transoral-transpalatine approach. In 1907, Schloffer treated a pituitary tumour through an open transnasal-transphenoidal approach, with consequent significant aesthetic and functional problems. Three years later Hirsch, an otolaryngologist, described for the first time the trans-septal endonasal approach to reach the contents of the sella turcica ${ }^{30}$. Some years later, Cushing modified this access using a sublabial incision, later shifted into a transcranial way due to the high risk of rhinoliquorrea, the difficult control of bleeding and post-operative cerebral edema. The evolution of the trans-sphenoidal approach to the sellar and parasellar region was induced by three factors: first and most important, the persistent efforts of the pioneers of surgery often against the colleagues' scepticism; second, the advancement of technology; and third, its application to routine surgery. This was the case of endoscopic technique and its introduction into skull base surgery. Jho and Carrau reported the first surgical series of 50 patients affected by sellar lesion operated between September 1993 and June 1996 with an endoscopic approach ${ }^{31}$. The use of an endoscopic technique (pure or assisted with neuronavigator) to access the sellar and parasellar region is probably the most important achievement in contemporary skull base surgery.

The main advantages of the endoscopic technique are a minimally invasive access without aesthetic defects, an excellent view of the operating field and the management of lateral, superior or inferior lesions ensuring a more radical treatment with reduced post-operative complications ${ }^{32}$.

The involvement of the cavernous sinus is considered one of the most negative prognostic factors in the surgical treatment of pituitary lesions. Two different trans-sphenoidal corridors can be used to achieve the intracavernous portion of the ICA: the medial side is better reached inserting the endoscope through the contralateral nasal fossa; on the contrary, lesions in the lateral side of the cavernous sinus can be approached through a trans-ethmoidal trans-pterygoidal access.

Significant lateral extension, encasement of neurovascular structures, and brain invasion in malignant lesions are considered some of the contraindications for an endoscopic approach. In some cases, a combined approach (transcranial and endoscopic) is required.

The complication rate of trans-sphenoidal surgery depends on different factors, such as location, extension, biological behaviour of the tumour and the expertise of the surgical team. In addition, it is well known that the complication rate in revision surgery is significantly higher than in first surgery. Endocrinological and ophthalmic complications can also occur.

CSF leak is the most common surgical complication in pituitary surgery and extended approaches, as confirmed in our series. When the leak is recognized during surgery, the reconstruction of the defect using autologous or heterologous grafts is mandatory ${ }^{33}$. Sometimes, the defect can remain unknown until complications appear (including meningitis and intracranial abscesses), requiring a revision surgery to repair 
the defect. High-flow leaks can involve in cerebral parenchymal herniation through the skull base defect, stretching the intradural or subarachnoid vessels, until break them causing an epidural, subdural or parenchymal hematoma. Symptoms vary according to the hematoma extension and location, as well as the treatment that can be conservative or surgical. The development of a subdural hematoma represents a rare but potentially fatal event, often the clinical picture is uncertain, in some cases it remains asymptomatic.

Another possible complication is bleeding, generally from the posterior septal branches of the sphenopalatine artery, more frequent in macroadenomas and during extended approaches. Arterial bleeding stops spontaneously in most cases or can be controlled by coagulation with bipolar cautery. Venous bleeding mainly originates from the cavernous sinus and can be easily solved. Profuse bleeding requires immediate suspension of the surgery.

The internal carotid artery damage represents the worst surgical complication and can lead to permanent disabilities or even death. An accurate preoperative radiological study is mandatory to prevent this complication. The neuronavigator and the micro-doppler also provide important support. The accidental damage of ICA during the trans-sphenoidal approach for pituitary adenomas is reported $0,2-1,4 \%$ in literature ${ }^{34,35}$. In 2016, AlQahtani et al. ${ }^{36}$ have distinguished the risk factors for ICA damage in: anatomical factors (thinning or thickening of the ICA bone canal in the lateral wall of the sphenoid sinus, the distance between the two intracavernous tracts, possible presence of aneurysms, pseudoaneurysms or arterio-venous malformations, dislocation of the ICA), factors related to the pathology (tumours in close contact or invading the artery, previous treatments), surgeon-depending factors (the surgeon's experience). Emergency treatment in case of vascular damage consists of blood transfusion and plasma expanders infusion in order to avoid hypovolemic shock, the use of hemostatic materials or vascular clips and, once the bleeding has been controlled, the endovascular treatment.

Meningitis is the most frequent intracranial complication after trans-sphenoidal surgery, especially in patients with cerebrospinal fluid leak. Typical symptoms are fever, headache, photophobia and coma in some cases. The diagnosis is performed by the analysis of the CSF; a brain CT scan is also useful to identify a possible leak. Hospitalization and broad-spectrum antibiotic therapy based on the antibiogram is necessary to avoid major complications.

The worst ophthalmic complication is irreversible blindness due to damage to one or both optic nerves. The damage can be direct or indirect, the latter usually due to intraorbital bleeding. The direct injury to the optic nerve, fortunately rare (1-2\% of the patients undergoing trans-nasophenoidal surgery), is generally determined by a trauma at the level of the lateral wall of the sphenoidal sinus. Other dangerous regions are the posterior ethmoid in case of Onodi's cell, and the optical chiasm in approaches extended to the suprasellar region. Even the abducent nerve can be damaged along its course in the cavernous sinus, since it is the only structure located inside the sinus.

At routine 24-hour post-operative brain CT-scan a modest pneumocephalus is frequently observed, but in most cases, it is reabsorbed spontaneously within a few days. A dangerous condition occurs when a defect of the dura mater acts as a valve: the air accumulates inside the brain every time the pressure of the upper airway increases. The progressive increase of intracranic pressure can damage the motor cortex or cause the development of subdural hematoma, up to cardiac arrest due to compression of the brain stem.

In experienced hands, endoscopic endonasal removal of sellar and parasellar lesions has become increasingly safe and effective. However, serious complications can occur.

Inspection of preoperative MRI and CT scan may predict surgical challenges as anatomical variations (conchal sphenoid sinus, vascular anomalies or narrow surgical corridor because of reduced distance between the parasellar carotid arteries), or tumour feature (invasion of the cavernous sinus, vertical extension). Last but not least, an accurate understanding of the anatomy and a multidisciplinary planning are essential to deal with this type of surgery.

\section{Conclusions}

Sellar and parasellar lesions represent a challenge because of their variable features and because of the importance of understanding the anatomy of this region, that is essential for providing improved resections with decreased morbidity. The evolution of the trans-sphenoidal approach has resulted from technological developments, increasing anatomical understanding and collaboration between Otolaryngologist and Neurosurgeon. Especially in this approach, a treatment planning involving several specialists (Otolaryngologist, Neurosurgeon, Neuroradiologist, Endocrinologist, Ophtalmologist) is mandatory in order to minimize complications, offering the patient the best treatment and a high quality of life.

\section{References}

Yasuda A, Campero A, Martins C, et al. The medial wall of the cavernous sinus: microsurgical anatomy. Neurosurgery 2004;55:179190. https://doi.org/10.1227/01.neu.0000126953.59406.77

2 Fernandez-Miranda JC, Gardner PA, Rastelli Jr MM, et al. Endoscopic endonasal transcavernous posterior clinoidectomy with interdural pituitary transposition. J Neurosurg 2014;121:91-99. https://doi. org/10.3171/2014.3.jns131865

3 Rennert J, Doerfler A. Imaging of sellar and parasellar lesions. Clin 
Neurol Neurosurg 2007;109:111-124. https://doi.org/10.1016/j. clineuro.2006.11.001

4 Kaltsas GA, Evanson J, Chrisoulidou A, et al. The diagnosis and management of parasellar tumours of the pituitary. Endocrine Relat Canc 2008;15:885-903. https://doi.org/10.1677/erc-08-0170

5 Dehdashti AR, Gentili F. Current state of the art in the diagnosis and surgical treatment of Cushing disease: early experience with a purely endoscopic endonasal technique. Neurosurg Focus 2007;23:1-8. https://doi.org/10.3171/foc.2007.23.3.11

6 Oldfield EH, Vortmeyer AO. Development of a histological pseudocapsule and its use as a surgical capsule in the excision of pituitary tumors. J Neurosurg 2006;104:7-19. https://doi.org/10.3171/jns.2006.104.1.7

7 Monteith SJ, Starke RM, Jane JA, et al. Use of the histological pseudocapsule in surgery for Cushing disease: rapid postoperative cortisol decline predicting complete tumor resection. J Neurosurg 2012;116:721-727. https://doi.org/10.3171/2011.12.jns11886

8 Prevedello DM, Ebner FH, de Lara D, et al. Extracapsular dissection technique with the Cotton Swab for pituitary adenomas through an endoscopic endonasal approach - how I do it. Acta Neurochirurgica 2013;155:1629-1632. https://doi.org/10.1007/s00701-013-1766-1

$9 \mathrm{Kim} \mathrm{EH}, \mathrm{Ku} \mathrm{CR}$, Lee EJ, et al. Extracapsular en bloc resection in pituitary adenoma surgery. Pituitary 2015;18:397-404. https://doi. org/10.1007/s11102-014-0587-4

10 Ironside N, Chatain G, Asuzu D, et al. Earlier post-operative hypocortisolemia may predict durable remission from Cushing's disease. Eur J Endocrinol 2018;178:255-263. https://doi.org/10.1530/eje-17-0873

11 Bresson D, Herman P, Polivka M, et al. Sellar lesions/pathology. Otolaryngol Clin North Am 2016;49:63-93. https://doi.org/10.1016/j. otc.2015.09.004

12 Hardy J, Vezina JL. Transsphenoidal neurosurgery of intracranial neoplasm. Adv Neurol 1976;15:261-273.

13 Micko AS, Wohrer A, Wolfsberger S, et al. Invasion of the cavernous sinus space in pituitary adenomasç endoscopic verification and its correlation with an MRI-based classification. J Neurosurg 2015;122:803811. https://doi.org/10.3171/2014.12.jns141083

14 Nunes RH, Abello AL, Zanation AM, et al. Imaging in endoscopic cranial skull base and pituitary surgery. Otolaryngol Clin North Am 2016;49:33-62. https://doi.org/10.1016/j.otc.2015.09.003

15 Dalan R, Leow MKS. Pituitary abscess: our experience with a case and a review of the literature. Pituitary 2007;11:299-306. https://doi. org/10.1007/s11102-007-0057-3

16 Claus EB, Bondy ML, Schildkraut JM, et al. Epidemiology of intracranial meningioma. Neurosurgery 2005;57:1088-1095. https://doi. org/10.1227/01.neu.0000188281.91351.b9

17 Wiemels J, Wrensch M, Claus EB. Epidemiology and etiology of meningioma. J Neurooncol 2010;99:307-314. https://doi.org/10.1007/ s11060-010-0386-3

18 Kshettry VR, Ostrom QT, Kruchko C, et al. Descriptive epidemiology of World Health Organization grades II and III intracranial meningiomas in the United States. Neuro Oncol 2015;17:1166-1173. https:// doi.org/10.1093/neuonc/nov069

19 Smith JK. Parasellar tumors: suprasellar and cavernous sinuses. Top Magn Reson Imaging 2005;16:307-315. https://doi.org/10.1097/01. rmr.0000224687.29371.9a

20 McCrea EJ, George E, Settler A, et al. Pediatric supra- sellar tumors. J Child Neurol 2016;31:1367-1376. https://doi. org/10.1177/0883073815620671

21 Brastianos PK, Taylor-Weiner A, Manley PE, et al. Exome sequencing identifies BRAF mutations in papillary craniopharyngiomas. Nature Genet 2014;46:161-165. https://doi.org/10.1038/ng.2868

22 Clark AJ, Cage TA, Aranda D, et al. A systematic review of the results of surgery and radiotherapy on tumor control for pediatric craniopharyngioma. Childs Nervous Syst 2013;29:231-238. https://doi. org/10.1007/s00381-012-1926-2

23 Guillamo JS, Doz F, Delattre JY. Brain stem gliomas. Curr Opin Neurol 2001;14:711-715. https://doi. org/10.1097/00019052-200112000-00006

24 Zoli M, Milanese L, Bonfatti R, et al. Clival chordomas: considerations after 16 years of endoscopic endonasal surgery. J Neurosurg 2018;128:329-338. https://doi.org/10.3171/2016.11.jns162082

25 Van Gompel JJ, Janus JR. Chordoma and chondrosarcoma. Otolaryngol Clin North Am 2015;48:501-514. https://doi.org/10.1016/j. otc.2015.02.009

26 Serrano E, Coste A, Percodani J, et al. Endoscopic sinus surgery for sinonasal haemangiopericytomas. J Laryngol Otol 2002;116:951954. https://doi.org/10.1258/00222150260369525

27 Thompson LDR, Miettinen M, Wenig BM. Sinonasal-type hemangiopericytoma: a clinicopathologic immunophenotypic analysis of 104 cases showing perivascular myoid differentiation. Am J Surg Pathol 2003;27:737-749. https://doi. org/10.1097/00000478-200306000-00004

28 Gomez-Riviera F, Fakhri S, Williams MD, et al. Surgical management of sinonasal hemangioperycitomas: a case series. Head Neck 2012;34:1492-1496. https://doi.org/10.1002/hed.21926

29 Barnes L, Eveson JW, Reichart P, et al. Pathology and genetics of head and neck tumours. Lyon, France: International Agency for Research on Cancer Press; 2005.

30 Hirsch O. Endonasal method of removal of hypophyseal tumors. With a report of two successful cases. JAMA 1910;55:772-774.

31 Jho HD, Carrau RL. Endoscopic endonasal transsphenoidal surgery: experience with 50 patients. J Neurosurg 1997;87:44-51. https://doi. org/10.3171/jns.1997.87.1.0044

32 Rigante M, La Rocca G, Lauretti L, et al. Preliminary experience with 4K ultra-high definition endoscope: analysis of pros and cons in skull base surgery. Acta Otorhinolaryngol Ital 2017;37:237-241. https:// doi.org/10.14639/0392-100X-1684

33 Presutti L, Mattioli F, Villari D, et al. Transnasal endoscopic treatment of cerebrospinal fluid leak: 17 years'experience. Acta Otorhinolaryngol Ital 2009;29:191-196.

34 Valentine R, Wormald PJ. Carotid artery injury after endonasal surgery. Otolaryngol Clin North Am 2011;44:1059-1079. https://doi. org/10.1016/j.otc.2011.06.009

35 Berker M, Hazer DB, et al. Complications of endoscopic surgery of the pituitary adenomas: analysis of 570 patients and review of the literature. Pituitary 2012;15:288-300. https://doi.org/10.1007/ s11102-011-0368-2

36 AlQahtani AA, Castelnuovo P, Nicolai P, et al. Injury of the internal carotid artery during endoscopic skull base surgery: prevention and management protocol. Otolaryngol Clin North Am 2016;49:237-252. https://doi.org/10.1016/j.otc.2015.09.009 